\title{
Ex Isto, de Cao Guimarães, e o ultrapassamento de si
}

\author{
Rafael de Almeida
}

Resumo: Este ensaio dedica-se ao filme Ex Isto (2010), de Cao Guimarães, dando maior relevo em seu percurso analítico ao modo como o corpo performático do ator desfaz-se de si para dar forma à existência da imagem do personagem real interpretado, bem como à maneira pela qual a obra se constrói, operando passagens entre a literatura e o cinema, o documentário e a ficção, a vida e a imagem.

Palavras-chave: documentário; performance; Ex Isto (filme); Cao Guimarães.

Abstract: Ex It, by Cao Guimarães, and the transcendence of self - This essay focuses on the film Ex It (2010), by Cao Guimarães, with emphasis on an analysis of how the actor transcends himself to give shape to the existence of the image of the real character he interprets, and the way in which the film develops, passing from literature to cinema, documentary to fiction, and life to image.

Keywords: documentary; performance; Ex It (Ex Isto, the film); Cao Guimarães.

Penso, logo existo.

René Descartes

O real precisa ser ficcionado para ser pensado.

Jacques Rancière

\section{Criar um documento}

"Fazer um filme documentário sobre autor nacional é relacionar-se inevitavelmente com essa circulação do literário" (CESAR, 1980, p. 9). Ou seja, de acordo com a escritora Ana Cristina César, pelo fato de os documentários sobre autor no Brasil serem produzidos em profunda conexão com o sistema escolar, eles assumem, na grande maioria das vezes, 
um caráter predominantemente informativo. Nesse sentido, o literário é apreendido por um viés que se preocupa menos em revelar a construção de alguma relação com o universo literário do autor, do que em converter a sua própria personalidade em um retrato a ser guardado para as próximas gerações.

Ex Isto (Cao Guimarães, 2010) integra o projeto Iconoclássicos, criado e produzido pelo Itaú Cultural. O instituto convidou diretores de cinema a se debruçarem sobre o universo criativo de artistas brasileiros contemporâneos e "criarem documentos audiovisuais repletos de informações e referências a estes artistas e suas obras" ${ }^{\prime 1}$. Nesse contexto, o que seria criar um documento? Para nós, o convite parecia antecipar informações acerca da forma e do conteúdo pretendido para os filmes pela instituição.

Ora, se a solicitação feita ao cineasta foi da criação de um documento, talvez o caminho mais evidente para o artista fosse realizar o então já conhecido passeio entre "berço, túmulo, objetos pessoais, iconografia familiar, caminhos que percorreu, tipos que conheceu, capas dos seus livros, prêmios recebidos, aclamações" (CESAR, 1980, p. 11).

No entanto, convidado a realizar um filme que dialogasse com a obra do poeta Paulo Leminski, Cao Guimarães escolheu inspirar-se livremente em umas das obras mais emblemáticas do autor, o romance Catatau, escrito em 1975, no qual ele se deixa levar por uma hipótese histórica: "E se René Descartes tivesse vindo ao Brasil com Maurício de Nassau?" Um documento/monumento começava a ser criado. ${ }^{2}$

Mais do que se apegar ao caráter de testemunho, ou ensinamento, que o filme poderia ter, Cao opta por dançar com a obra Catatau, por fazer uma leitura e assumi-la como tal, por intervir conscientemente, por ir à busca da materialização imagética de sua sensação estética. Dessa maneira, monumentaliza o caráter de documento do filme. O que nos leva a pensar que, se a "política e a arte, tanto quanto os saberes, constroem 'ficções', isto é, rearranjos materiais dos signos e das imagens, das relações entre o que se vê e o que se diz, entre o que se faz e o que se pode fazer" (RANCIÈRE, 2005, p. 59), como nos diria Rancière, o diretor de Ex Isto opta por ficcionar, acima de tudo.

"O que busquei fazer com o filme foi voltar ao estágio da pré-fala a que o livro me conduzia. Aquela fase em que a linguagem tem apenas um horizonte de sentido, quando se é conduzido pela musicalidade - o filme busca essa sensação", nos confirma Cao. "A possibilidade do derretimento da razão cartesiana". (TAKAMATSU, 2010, p. 45). Reconhecemos aqui um desejo de mescla ao universo literário e sua linguagem,

1 Release do projeto destinado à imprensa; grifo nosso.

2 Aqui a intenção é significar que "o documento não é inócuo". É, antes de qualquer coisa, "o resultado de uma montagem, consciente ou inconsciente, da história, da época, da sociedade que o produziram, mas também das épocas sucessivas durante as quais continuou a viver," assim como o filme documentário. Por essa perspectiva, percebemos o documento e o documentário, como algo "que fica, que dura, e o testemunho, o ensinamento (para evocar a etimologia) que ele traz devem ser em primeiro lugar analisados, desmistificando-lhe o seu significado aparente". O que nos permite, em última instância, afirmar que o "documento é monumento". Ou seja, é resultado do "esforço das sociedades históricas para impor ao futuro - voluntária ou involuntariamente - determinada imagem de si próprias". Por fim, "não existe um documento-verdade. Todo documento é mentira" (LE GOFF, 2003, p. 537-538). 
que submete a personalidade de Leminski ao segundo plano, impulsionado pelo anseio de expor visualmente as relações travadas com o próprio texto: "Lembro do impacto que ela causou em mim quando a li. A investigação profunda da linguagem, os neologismos, os provérbios populares [...]. Eu o lia em voz alta e não mais que três ou quatro páginas por dia, não aguentava mais que isso" (TAKAMATSU, 2010, p. 45).

\section{Do antes}

Leminski (2010) nos conta, em Descordenadas artesianas, texto incorporado a Catatau, que a concepção básica para o livro surgiu enquanto ministrava uma aula de História do Brasil sobre as invasões holandesas e sobre a intenção dos holandeses da Companhia das Índias Ocidentais de se estabelecerem em Recife. Tratou do esforço empreendido pelo príncipe Maurício de Nassau, diretor da Companhia do Brasil, de trazer intelectuais, pintores, cartógrafos, assim como Marcgravf, Wagener, Post, Golijath, Eckout, para estudar e compreender essa "Nova Holanda"; tratou também do fato de que Maurício de Nassau vivia entre ilustres pensadores, , inclusive, o filósofo francês: "René Descartes (que, à moda do tempo, latinizava o nome para Renatus Cartesius) era fidalgo da guarda pessoal de Maurício".

Desta forma, se deu conta da hipótese histórica que serve como ponto de partida para o romance: "E SE DESCARTES TIVESSE VINDO PARA O BRASIL COM NASSAU, para a Recife/Olinda/Vrijburg/Freiburg/Mauritzstadt, ele, Descartes, fundador e patrono do pensamento analítico, apoplético nas entrópicas exuberâncias cipoais do trópico?" (LEMINSKI, 2010, p. 211).

Em Ex Isto, acompanharemos a realização dessa hipótese, pelo ponto de vista de Cao Guimarães. De acordo com a sinopse da obra, seguimos o pai da filosofia moderna em seu périplo pelos trópicos sob o efeito de ervas alucinógenas, investigando questões da geometria e da ótica diante de um mundo absolutamente estranho.

Descartes nos é apresentado em um ambiente escuro, aparentemente iluminado apenas por uma lamparina. De um plano-detalhe do que parece ser o olho de um animal, que o personagem segura em sua mão, examinando-o próximo à fonte de luz, saltamos para um detalhe do olhar curioso de Descartes em si. Durante essa pequena cena, que nos introduz, de uma maneira tão próxima ao filósofo-pesquisador, a ponto de nos permitir cartografar seu rosto, ouvimos trechos, em off, do princípio de Discurso do método: "O bom senso é a coisa mais bem distribuída do mundo: pois cada um pensa estar tão bem provido dele, que mesmo aqueles mais difíceis de se satisfazerem com qualquer outra coisa não costumam desejar mais bom senso do que têm" (DESCARTES, 1996, p. 5).

Seguindo tal linha de raciocínio é que ele afirmará,, mais adiante,, sentir uma grande satisfação pelo progresso que acredita já ter realizado na procura da verdade, de maneira tal que: "se entre as ocupações dos homens puramente homens há alguma que seja 
solidamente boa e importante, atrevo-me a crer que é que a escolhi" (ibid., p. 7). Vemos aqui sua figura lendo enquanto caminha em um corredor na parte superior do quadro, absorta em meio a centenas de livros, em uma grande biblioteca. Parece-nos, até então, que o filósofo também acreditava já possuir o bom senso que lhe era necessário.

No entanto, a câmera se aproxima e o personagem, logo depois de atentamente analisar a ilustração de uma onça-pintada, começa a empreender um ato de fala: "Não sou máquina, não sou bicho. Eu sou René Descartes com a graça de Deus". Acompanhando em plano próximo o rosto de Cartesius, que continua caminhando de um lado para o outro, o foco se perde e se encontra repetidas vezes em sua face. "Abaixo as metamorfoses desses bichos, - camaleões roubando a cor da pedra!" (LEMINSKI, 2010, p. 29).

Enquanto isso, o que ele lê gera o mesmo movimento no personagem: o (des)encontro de si nas categorias do pensamento. "Debrucei-me sobre livros a ver passar rios de palavras. Todos os ramos do saber humano me enforcaram, sebastião flechado pelas dúvidas dos autores" (LEMINSKI, 2010, p. 31). E logo começamos a sentir o estranhamento de encontrar um Descartes habitado por vários sujeitos. Como se antevisse, antes mesmo de cruzar a linha do Equador, que suas ideias não conseguiriam se manter tão claras e sistemáticas, pelo mero fato de um lugar como aquele - o Brasil - existir.

Do mapa de Georg Marcgravf da ilha de Antônio Vaz e do Recife, na Capitania de Pernambuco, datado de 1647, com indicação dos rios Capibaribe, Beberibe e dos Afogados, no qual Descartes acompanha com a ponta do dedo o percurso de um rio, seremos levados para dentro dele. Dali, tomando emprestados os olhos do personagem, contemplamos a paisagem da robusta vegetação da margem do rio, que lentamente vai sendo deixada para trás, enquanto experimentamos sua aflição pela chegada, potencializada pelo salmo penitencial que ouvimos ao fundo. Notamos aí que o diretor, ao "invés de retratar, expor, explicar, naturalizar", escolhe outra via: "subjetivar, metaforizar, silenciar, encenar" (CESAR, 1980, p. 47).

Partindo da premissa assumida pelo autor do romance, de que "Catatau é o fracasso da lógica cartesiana branca no calor, o fracasso do leitor em entendê-lo, emblema do fracasso do projeto batavo, branco, no trópico" (LEMINSKI, 2010, p. 212); Ex Isto ousa ser ficção e seguir passos semelhantes, o que não significa que está se furtando de seu caráter de documento, mas se reconhecendo enquanto objeto cultural, para além disso, que se inspira livremente na atmosfera poética do escritor, transcriando-a, trazendo para dentro do filme esse universo simbólico.

Essa aranha geometrifica seus caprichos na Ideia dessa teia: emaranha a máquina de linhas e está esperando que the caia às cegas um bicho dentro: aí trabalha, aí ceia, aí folga. Caminha no ar (...), obra de nada: não vacila, não duvida, não erra. (Ibid., p. 30)

Enquanto ouvimos em off a voz de Cartesius, vemos planos-detalhes de uma aranha fazendo sua teia. Com precisão acompanhamos a agilidade e a exatidão de suas "mãos 
de fiandeira". A existência de animais com capacidades tão fascinantes, como essa aranha, capazes de desafiar as leis da física de até então, é o suficiente para por em xeque a lógica de Descartes. "A aranha leva daqui ali o tempo que levei para conseguir o teor de semelhantes teorias" (ibid., p. 37-38).

Lógica tal que se desfaz na construção do próprio texto, já que "existe literalmente um abismo de frase para frase, abismo esse que o leitor deve transpor como puder" (ibid., p. 215), confirma-nos Leminski; e é transferida para o filme por meio da montagem: entre um corte e outro, na maioria das vezes, não podemos esperar nada além de lacunas de sensações a serem preenchidas para que não nos percamos no labirinto sensório pelo qual caoticamente transita Descartes.

Interpretado por João Miguel, acompanhamos Descartes em uma viagem pelos trópicos, em uma narrativa que cria uma tensão entre o ficcional e o documental, pois, se por um lado, temos a presença de um ator, seu caráter antinaturalista e alegórico não nos permite ocupar, sem algum desconforto, o papel do espectador típico de ficção. Na via contrária, se a mise-en-scène nos aproxima do domínio documental, não é possível desconsiderar o corpo performático de João Miguel nos conduzindo.

Se na esteira de Comolli, percebemos, por um lado, o documentário como "o contrário da informação, das informações; o reino da ambiguidade; o território das metamorfoses; o domínio da narrativa"; e por outro, a ficção como "força que nos faz sair dos eixos", "porta que nos faz passar para o outro lado do espelho narcísico no qual os meios de comunicação nos aprisionam" (COMOLLI, 2007, p. 127), perceberíamos que a tensão da qual falamos se converte em potência de escritura para uma narrativa que mescla documentário, ficção e poesia.

No entanto, para não deixar de lado a problematização em torno do domínio comungado por Ex Isto, não nos custa deixar de considerar o que apresenta maior peso na construção narrativa, ao lançar um olhar sobre a relação entre quem filma e é filmado: a mise-en-scène de João Miguel é acolhida na de Cao Guimarães, ou é tomada como "objeto" para o "tratamento fílmico", estética, roteiro, experimentação do diretor? O "primeiro gesto é o do documentário; o segundo, o da ficção - eis uma diferença decisiva" (GUIMARÃES; CAIXETA, 2008, p. 38). Ainda nos restam dúvidas?

Dessa maneira, o "recurso aos expedientes ficcionais poderia ser considerado, quem sabe, um meio de alcançar dimensões mais complexas da experiência dos sujeitos filmados, vindo a reorganizar a relação entre a escritura do filme e o real que a constitui, perfurando-a" (GUIMARÃES, 2011, p. 71). Há aí uma possibilidade, talvez, de alcançar com maior cuidado e precisão a experiência do ator João Miguel em um dispositivo que o induz a realizar uma performance, a assumir a forma de um Descartes em uma situação imaginária.

\section{Assumir a forma}

Segundo Cao Guimarães, sobre o ator: "Ele me perguntava do roteiro, de como compor um personagem sem roteiro, sem falas... Ele nunca tinha feito um filme sem 
roteiro. E eu não faço roteiros. Eu disse: você é um filósofo, então leia e pense, pense, pense..." (TAKAMATSU, 2010, p. 45). Esse distanciamento, que consideramos sugerir linhas gerais para o ator sem, no entanto, guiá-lo, não permitiria que pensássemos na possibilidade de que a atuação de João Miguel nutra uma forte relação com a performance? Circunstanciemos.

Em Ex Isto, João Miguel não é, como diria Comolli, um homem ordinário do documentário, ou seja, aquele que não possui como função "ser ator", estando livre para cumprir seu próprio papel. No entanto, embora estejamos diante de um ator profissional, acreditamos que assim como por vezes acontece a esses, acompanhamos um ultrapassamento de si. "Ultrapassamento a ser considerado em toda sua violência, que é a de suspender - em parte, por um tempo - o jogo relacional próprio ao cinema (...). Saindo de si, o sujeito filmado coloca em suspenso sua relação com os outros sujeitos" (COMOLLI, 2007, p. 133-134).

Pensamos que essa espécie de construção do personagem por si mesmo, através da leitura do livro, interagindo, na maior parte do tempo, com outras formas-de-vida que cumprem seu próprio papel, em uma narrativa antinaturalista - na qual tanto o ator, quanto o espectador, possuem consciência de se tratar de uma encenação - leva João Miguel a relacionar-se de uma maneira ainda mais intensa com a máquina cinematográfica. Nesse sentido, isso o leva a dar-se e expor-se para além do que a "função-ator" normalmente exigiria.

João Miguel assume o risco de dar esse passo a mais e perder-se. Daí nossa dificuldade em perceber René Descartes somente como um personagem, em contraposição ao papel de "sujeito do filme" assumido pelo ator, que reconhece os trilhos que o filme necessita alcançar. Ou seja, o que cremos ver é um duplo procedimento: por um lado, o processo de perda da razão do personagem Descartes em sua viagem pelos trópicos; por outro, acompanhamos os processos de subjetivação pelos quais passa o ator, João Miguel, desfazendo-se arduamente de si para dar forma à existência da imagem do filósofo, performativizando, enquanto era registrado pela câmera de Cao. João Miguel se violenta, para que o mundo violente René Descartes. O ultrapassamento de si, assumido pelo ator converte-se em força vital para um personagem que vê seu mundo racional implodir aos poucos.

Na esteira de Brasil (2011), é possível dizer que estamos diante de uma experiência em que a imagem parece "não apenas representar ou figurar", mas "produzir formas de vida". Ou seja, "as performances que ali se produzem (dos autores e dos personagens) estão, simultaneamente, no mundo vivido e no mundo imaginado, elas são, a um só tempo, forma de vida e forma da imagem" (BRASIL, 2011, p. 4). Para tanto, a mise-en-scène do diretor de Ex Isto, durante a maior parte do filme, trata de fortalecer a auto-mise-en-scène do ator: "favorece seu desenvolvimento, dá-lhe tempo e campo para se definir, se manifestar. Filmar torna-se, assim, uma conjugação, uma relação na qual se trata de se entrelaçar ao outro - até na forma" (COMOLLI, 2008, p. 85). 
Na rodoviária de Brasília, por exemplo, seguimos, em um plano-sequência de quatro minutos de duração, o caminhar de Descartes de um lado a outro, sem direção definida. A câmera na mão se pauta por uma estética observacional, acompanhando da maneira que pode a ação do personagem. Em determinados instantes, câmera e foco se perdem na busca do ator, que igualmente se perde em meio à multidão. A velocidade de seus passos varia, como se refletisse a sensação de estar no mundo do personagem.

Compartilhamos com Descartes de sua agonia e,, para além dela, cremos ver a do próprio João Miguel em sustentar uma ação tão simples e que precisa representar tanto. Mal-estar que parece ser potencializado pelo transcorrer da tomada, para todos: ator, personagem e espectador. As reações das pessoas são múltiplas: algumas tentam ignorar, outras olham fixamente para a câmera, espantam-se com as roupas do ator, ou ainda se irritam porque, ao passar, João/René esbarra nelas.

Aqui, como em vários outros momentos do filme, testemunhamos a intensa relação que o corpo do ator trava com o próprio tempo e seus desdobramentos em movimentos que variam entre a lentidão e a velocidade. A duração é o resultado dessa exposição do corpo, bem como sua resistência enquanto matéria, pela performance. O delírio de Descartes é relatado e sentido por meio do corpo de João Miguel. Um corpo que escreve, discursa, afirma através de sua exposição no tempo: corpo-relato.

Podemos, então, afirmar com Zumthor, que em Ex Isto a performance do ator "realiza, concretiza, faz passar algo que eu reconheço, da virtualidade à atualidade", pois ela não se comporta como "simplesmente um meio de comunicação: comunicando, ela o marca" (ZUMTHOR, 2007, p. 31). Isto é, o corpo-relato do ator nos permite sentir, mais do que ver, o corpo-imagem do personagem. Logo nas cenas seguintes, o tempo comum da vida é suspenso diante de um cenário que leva Cartesius, sob o efeito de ervas alucinógenas, a delirar com as formas geométricas não digeríveis da cidade símbolo da "utopia brasileira".

\section{Entre o corpo e o espaço}

Ao que nos parece, Descartes está em uma feira no entorno do Mercado de São José, em Recife. Parado, com as mãos na cintura, parece observar as pessoas que passam por ele. Suavemente começamos a escutar uma música latina. Lenta e discretamente, ele começa a mover seu corpo, como se ensaiasse, ou reprimisse, um desejo de dançar. Em um corte seco estamos diante de um plano que nos mostra uma banda tocando em praça pública. Na porção central do quadro, de costas para a banda, como se sua figura fizesse parte da apresentação, uma mulher, de aproximadamente 40 anos, dança com os olhos sempre voltados para a câmera.

Seus passos se tornam cada vez mais elaborados. Ela parece possuir total consciência de que está sendo filmada, interage com a câmera através de gestos, exibe-se, sorri como se tentasse seduzir-nos, como se estivesse fascinada com a existência do aparato ao 
seu redor. A princípio, com certa timidez, Descartes entra em quadro. Com a ampliação do quadro, vemos que há outra pessoa dançando, um rapaz. Em instantes, o nosso personagem tira as mãos da cintura e parece se permitir ser levado pela canção, inclusive fechando os olhos por alguns instantes para ampliar outros sentidos. René interage, pelo olhar, com a "dançarina". Ou melhor, tenta. A preocupação dela em fazer uma boa apresentação parece impedir outro tipo de relação, que não a que ela já está nutrindo pela câmera.

Comolli descreve a presença ou fotogenia como a "absoluta disponibilidade da máquina cinematográfica para registrar a experiência dos corpos reais, para fazer dessa experiência a força dos corpos filmados" e,; ao mesmo tempo, "a absoluta resistência dos corpos reais a se deixarem despossuir de si mesmos por uma máquina" (COMOLLI, 2008, p. 258), por outro.

Encontramos aqui o que nos parece ser uma exceção: a câmera, e não somente ela, impulsiona o processo de entrega do corpo, de desnudamento dos personagens reais. O dispositivo impulsiona o processo de devir do personagem, excita seus desejos, e talvez, por poucos instantes, o faz crer que está em vias de se tornar outro, a ponto de sentir-se como tal. Mas não sejamos ingênuos, "de cada lado da máquina há alguma coisa do corpo. Alguma coisa do sujeito" (ibid., p. 110).

Ainda segundo Comolli, "essa relação entre quem filma e quem é filmado via máquina significa a redução da distância que sempre se coloca no trabalho de mise-en-scène, e, ao mesmo tempo, aumenta a própria possibilidade de representar o íntimo" (ibid., p. 110). Outra pessoa se soma à dança. Outro homem. Entre os que dançam, nesse espaço público, não parece haver relação prévia alguma. O que os leva a assumir tal forma? De que maneira perceberíamos a performance em tal contexto? "A performance será então, nesse sentido, um processo de alienação: momento em que me alieno de mim mesmo, tornando-me outro", nos responde Brasil (2011, p. 10). "Ela é, precisamente, o encontro do ser com aquilo que o ultrapassa" (ibid., p. 10).

Nossa sensação é, portanto, de que o gesto empenhado pela "dançarina" gera um movimento de pulsação em seu corpo, capaz de atingir aos que estão ao seu redor, como se os convidasse a compartilhar daquele mesmo ritmo, da mesma vibração. E, assim, essa energia comum, que emana dos corpos, é o que os une no espaço, naquela situação dada em que era possível ser outro.

Se por um lado "a experiência é o que o cinema (documentário) filma em primeiríssimo lugar" (COMOLLI, 2008, p. 258), e por outro, o personagem de Ex Isto, e seu ator, se movimenta e se (des)orienta pelas experiências sensórias a que submete a si e seu corpo durante suas andanças pelo Brasil, então não haveria como recusar um convite como esses. Dessa maneira, somos apresentados ao "Descartes dançarino": mais um sujeito.

Se aqui "a dança é gesto, é porque, ao contrário, esta é somente o suportar e o exibir do caráter medial dos movimentos corporais. O gesto é a exibição de uma medialidade, o tornar visível um meio como tal" (AGAMBEN, 2000, p. 58), enquanto a performance 
vai um pouco mais além, comportando-se como "o gesto em vias de se colocar em cena, mas que, nesse 'em vias de', reinventa a cena sem, finalmente, se reduzir a ela" (BRASIL, 2011, p. 7). Desta forma, a performance de João Miguel se vale da ocasião em que o gesto da dança estava sendo empreendido por aqueles sujeitos.

Demonstra, portanto, que "a performance não apenas se liga ao corpo mas, por ele, ao espaço", já que este é "ao mesmo tempo lugar cênico e manifestação de uma intenção de autor" (ZUMTHOR, 2007, p. 39-40). Por essa perspectiva poderíamos inferir que a praça pública em que originalmente ocorria somente a apresentação musical é reconfigurada, enquanto espaço, a partir do momento em que Descartes se junta aos demais e começa a dançar, e coloca-se em cena. Já que a situação da performance inventa um outro espaço, atualiza uma virtualidade que se sobrepõe ao primeiro, no qual é possível ao espectador assimilar e reagir àquela presença no mundo e o imaginário por ela suscitado.

\section{Ultrapassamento de si}

Estamos diante da imagem do corpo nu de João Miguel se arrastando na areia da praia, ao final de tudo. De acordo com Comolli (2008, p. 256), é a imagem do corpo que resiste no cinema, "na medida em que continua irrevogavelmente ligada à globalidade e à complexidade do corpo". Isso significa dizer que os traços reunidos por essa imagem "convocam, ao mesmo tempo, a parte encarnada e parte impensada do corpo, marcas de vida, marcas de experiência vivida" (ibid., p. 256).

Descartes está em transe. Toda a solidez do pensamento cartesiano se vê derreter metaforicamente por meio de uma barra de gelo na beira da praia, banhada pelas águas do mar. "Este pensamento sem bússola é meu tormento. Quando verei meu pensar e meu entender voltarem das cinzas deste fio de ervas? Ocaso do sol do meu pensar" (LEMINSKI, 2010, p. 208).

A liquefação aumenta a cada encontro até que não reste mais nada, até que não seja mais possível resistir. A longa sequência é sustentada basicamente pela duração da exposição do corpo do ator. Cao Guimarães a infla de tempo para potencializar nossa angústia junto ao processo de alucinação do personagem. Não há espetáculo, senão imagens que fogem dessa lógica através da performance que se realiza diante de nossos olhos, da reinvenção de um corpo em cena, de sua abertura para o mundo.

Em Ex Isto as imagens duram pela resistência empreendida por esse corpo-relato diante da câmera. "Novamente: a maré de desvairados pensamentos me sobe vômito ao pomo adâmico. Estes não. E esta terra: é um descuido, um acerca, um engano de natura, um desvario, um desvio que só não vendo" (ibid., p. 208).

René Descartes (ou seria João Miguel?) sofre por perceber que não há outro movimento possível senão o ceder. Tomando emprestadas as palavras de Brasil, a propósito de Moscou (Coutinho, 2009), diríamos que a encenação proposta e documentada por Cao Guimarães, a partir do texto de Leminski, "abre no interior da experiência vivida uma cena híbrida, 
na qual, entre o real, o teatral e o fílmico, as performances não param de se engendrar e se transformar, em situação de deriva e inconstância" (BRASIL, 2011, p. 14).

A figura de uma mãe negra, fruto da alucinação de Descartes, acolhe-o no mar. Abraça-o como a um filho, carregando-o em seus braços. Lava-lhe a cabeça e o traz para junto do peito. Entre a inconsciência e lágrimas, ele esboça um sorriso. Não havia o que temer. Ele, René/João, era um outro.

Se "o filme documentário sobre literatura fala mais de literatura na medida em que se identifica ao projeto literário de autonomia e intransitividade da linguagem", isto é, na medida em que "fica menos 'documentário', livrando-se, como quer a linguagem literária, da obrigação de dizer (ou ensinar) alguma coisa", acreditamos nisso; Ex Isto cumpre exemplarmente seu papel. Pois ao optar por ficcionar, permite-se "não informar, não biografar, não construir um monumento nacional, transgredir a citação e o depoimento: encenar, desvirtuar a captação natural do escritor, transar um personagem" (CESAR, 1980, p. 57).

Por essa perspectiva, o ultrapassamento do corpo, enquanto matéria, acompanha, intensifica e relata o ultrapassar de outras barreiras: da linguagem em si. A obra se constrói operando passagens, entre a literatura e o cinema, o documentário e a ficção, a vida e a imagem.

Rafael de Almeida é doutor em Multimeios pela Universidade Estadual de Campinas (2013). Realizou Estágio de Doutorado (bolsa PDSE, Capes) na Faculdade de Ciências da Informação da Universidade Complutense de Madrid (2012-2013). É membro do CEPECIDOC - Centro de Pesquisa em Cinema Documentário (Unicamp/CNPq) - e NPTI - Núcleo de Pesquisa em Teoria da Imagem (UFG/CNPq). Como realizador audiovisual, dirigiu alguns curtas, entre os quais Carrossel, A saudade é um filme sem fim e Impej.

ratborges@hotmail.com

\section{Referências}

AGAMBEN, G. Notes on gesture. In: Means without end: notes on politics. Minneapolis: University of Minnesota Press, 2000.

BRASIL, A. A performance: entre o vivido e o imaginado. In: ENCONTRO DA COMPÓS - Grupo de Trabalho Comunicação e Experiência Estética, 20, Porto Alegre. Anais... Porto Alegre, Universidade Federal do Rio Grande do Sul, 14 a 17 jun. 2011.

CESAR, A. C. Literatura não é documento. Rio de Janeiro: Funarte, 1980.

COMOLLI, J-L. Os homens ordinários, a ficção documentária. In: SEDLMAYER, Sabrina; GUIMARÃES, 
César; OTTE, Georg (orgs.). O comum e a experiência da linguagem. Belo Horizonte: Editora da UFMG, 2007.

. Ver e poder: a inocência perdida - cinema, televisão, ficção, documentário. Belo Horizonte: Editora UFMG, 2008.

DESCARTES, R. Discurso do método. São Paulo: Martins Fontes, 1996.

GUIMARÃES, C. G. A cena e a inscrição do real. Revista Galáxia, São Paulo, n. 21, p. 68-79, jun. 2011.

; CAIXETA, R. Pela distinção entre ficção e documentário, provisoriamente. In: COMOLLI, JeanLouis. Ver e poder: a inocência perdida - cinema, televisão, ficção, documentário. Belo Horizonte: Editora UFMG, 2008.

LE GOFF, J. Documento/monumento. In: História e memória. Campinas: Editora da Unicamp, 2003.

LEMINSKI, P. Catatau: um romance-ideia. São Paulo: Iluminuras, 2010.

RANCIÈRE, J. A partilha do sensível: estética e política. São Paulo: Editora 34, 2005.

TAKAMATSU, R. Ex-isto. Revista Taturana, Londrina, Inverno, 2010.

ZUMTHOR, P. Em torno da idéia de performance. In: Performance, recepção, leitura. São Paulo: Cosac Naify, 2007.

Artigo recebido em dezembro de 2013

e aprovado em abril de 2014. 